\title{
RELEITURAS DE UMA OBSESSÃO HITCHCOCKIANA: origem, imagem, vertigem
}

\author{
Fernando de Mendonça \\ "O tempo é uma imagem móvel da eternidade." \\ Jorge Luís Borges
}

Recuperar o tempo, resgatar a experiência, aprofundar a consciência do estado criativo na valoração de lembranças que insistem pelo retorno, pela revisitação constante e permanente, são prerrogativas de uma compreensão da estética que se acentua em certo momento da Modernidade. A maturação que desenvolveu o caráter auto-reflexivo da arte, no sentido de se permitir em obra a exposição no reconhecimento das influências, reposicionou a poiésis que assume a relação de diálogo e dependência a outros imaginários e meios de expressão. Torna-se difícil pensar a escrita de uma linguagem sem atravessar a noção de que, em si própria, trata-se de uma reescrita, uma releitura de heranças anteriormente percebidas e vivenciadas também dentro do âmbito artístico. Um autor é o somatório de outros, uma obra, a interlocução de outras vozes. Quando este exercício é problematizado de forma consciente, apontando os mecanismos relacionais e a presença de seus intertextos, vê-se potencializados os parâmetros de recepção e interpretação que a nova obra propõe.

É disso que trata o conflito em que mergulha o célebre personagem de Borges, Pierre Menard, e é dele que eu me lembro ao deparar-me com obras que espelham universos anteriores de criação. Há, no cinema, incontáveis exemplos de retomada na escritura do tempo, que abrem a discussão para diversos níveis de representação: diretores que encenam a luz de outros mestres, intérpretes que reconfiguram sua corporalidade de acordo com algum mito do starsystem, cenas e enquadramentos que decupam alguma situação ou movimento já conhecido, o que resulta na prática corrente da refilmagem ou nova adaptação de uma ideia narrativa já representada. Guardadas as proporções, cada um destes casos intercepta o anseio criativo de Menard, em sua necessidade de reescrever determinada textualidade já existente como se esta agora se renovasse em uma experiência original.

Em se tratando de obras e carreiras consolidadas e já ancoradas numa espécie de cânone, a variedade de abordagens torna-se mais profundamente ampliada e o fluxo de 
trocas e influências passa a operar uma via de mão dupla - a obra fonte afeta e é afetada por aquelas que a homenageiam. Claro está que o nome de um cineasta como Alfred Hitchcock, responsável por um legado que não simboliza menos do que o nascimento de um gênero e uma compreensão particular da narrativa para o cinema, é alvo fácil de olhares que convirjam sutil ou explicitamente na citação de quadros, situações e personagens inspirados pela sua extensa filmografia. $\mathrm{O}$ ponto de partida para esta reflexão surge, justamente, do reflexo situado em dois expoentes do cinema contemporâneo, pela reescrita que propõem de um leitmotiv-alicerce junto à memória cinéfila hitchcockiana. Mas, antes de apontar estes novos leitores de Hitchcock, interessa alguma observação sobre o título de sua obra que sofrerá a posterior revisitação, inclusive, porque ela própria evoca uma reflexão da escrita que se refaz perpetuamente, da linguagem que se desdobra e, sobre si própria, extrai novas dimensões e infindáveis deslocamentos do olhar.

\section{Vertigo e o Fascínio da Espiral}

Ao falar sobre o que o levou a filmar o romance Dentre les Morts ${ }^{5}$, Hitchcock afirma: "O que mais me interessava eram os esforços feitos por James Stewart para recriar uma mulher, a partir da imagem de uma falecida". E é exatamente sobre isto que trata Vertigo (1958), filme recentemente eleito como o melhor da história do cinema ${ }^{7}$, não por acaso, um filme sobre a imagem, sobre a reescrita da imagem e as consequências deste processo sobre a mente que o instaura.

São bastante conhecidos os sofrimentos aqui enfrentados por James Stewart, na paixão nutrida por uma mulher que morre e é reencontrada / reconstruída sobre o corpo de outra, muito semelhante à falecida, e finalmente descoberta como a mesma mulher, que apenas encenara a sua morte. O complexo jogo de camadas sobreposto ao corpo da atriz Kim Novak testemunha um obsessivo tratamento da reescritura e do espelhamento que diz respeito à imagem de cinema. Inicialmente falsificada, Novak interpreta uma personagem que por sua vez interpreta a existência de outra; depois de dar fim ao seu 'teatrinho' e fingir a morte desta primeira mulher, ela é perseguida pelo olhar do homem que carregava a culpa de sua própria morte; morte da ficção, morte do desejo, morte da imagem original. A segunda parte do filme, baseada na reedificação deste corpo morto, abre espaço para a exata discussão que aqui levantamos, pois é nela que se estabelece a

|||||||||||||||||||||||||||||||||||||||||||||||||||||||||||||||

5 Escrito pelos franceses Boileau \& Narcejac, após uma série de sucessos policiais construídos sobre o mesmo princípio narrativo. Ao saberem do interesse de Hitchcock pelos direitos de Celle qui N'était Plus, que ganhou os cinemas como As Diabólicas (Henri-Georges Clouzot, 1955), os autores escreveram D'entre les Morts especialmente para o mestre do suspense.

6 As falas do diretor aqui transcritas foram extraídas de Hitchcock / Truffaut: entrevistas, edição definitiva, tradução de Rosa Freire D’Aguiar, São Paulo: Companhia das Letras, 2004.

7 Sight and Sound, British Film Institute (BFI), 2012. Disponível em: http://www.bfi.org.uk/news/50-greatest-films-all-time 
perspectiva de uma recuperação do passado em imagem, fragmento de um eterno retorno que se revela doentio sob a ótica daquele que manipula o corpo de Novak para sua satisfação pessoal (o persona de Stewart, mas também Hitchcock). Como lembra o diretor: “Todos os esforços de James Stewart para recriar a mulher são mostrados, cinematograficamente, como se ele procurasse despi-la em vez de vesti-la”.

Muito importa observar a cuidadosa reconstituição corporal outorgada ao figurino e maquiagem de Novak. Precisam ser as mesmas roupas, a mesma cor de esmalte, de batom, os mesmos gestos a se recuperar, a mesma entonação de voz, o mesmo olhar. Finalmente: precisa ser o mesmo penteado, o mesmo coque de cabelo, amarrado em espiral, a materializar a imagem-chave de nossa reflexão (Fig. 1 - Álbum de Imagens).

Beirando o fetiche, a forma da espiral é desdobrada ad infinitum dentro do universo visual de Vertigo. Da antológica abertura desenhada por Saul Bass a incontáveis signos espalhados pelo filme (escadarias, buquês de flores, closes em olhos, cenas de pesadelo, etc.), ela se torna o símbolo máximo da vertigem sofrida por James Stewart com seu medo de altura e um estímulo visual para que nos identifiquemos com este abismo de sentimentos provocado por toda a trama. Considerando a complexidade de sentido oriunda da forma espiral, Hitchcock se valeu do potencial que esta imagem serviria ao seu estilo de composição das imagens; o ecoar da forma em todas as constantes circulares de Vertigo, enfatiza e amplia a dimensão de interminável reescrita. Não há ponto de começo ou fim para um pensamento espiralado, não há borda ou limite para imagens e textos que reflitam um perpétuo recomeço, pautado pela repetição, pela volta ao mesmo que nunca é igual. Neste sentido, o coque de cabelo em Kim Novak abre caminho para duas leituras, entre inúmeras outras, que aqui nos interessam.

Primeiramente, fica estabelecido pela espiral um motivo icônico exemplar disto que nos leva a pensar o processo de reescrita. Se lembrarmos de que a primeira aparição de Novak, em Vertigo, no esforço de confundir seu perseguidor (Stewart), copiava o penteado de um retrato visto no museu, nos aproximaremos de uma intenção visual que só encontra sentido a partir do processo de repetição. Não à toa, o primeiro close sobre o coque espiralado prossegue num movimento de câmera que enquadra o retrato copiado. São imagens que rimam, ecos que se afirmam complementares, paralelos. Na interpretação de Jacques Rancière, são motivos que determinam a captura do olhar dentro da mis en scène, são a chave da fascinação e do processo de exposição/dissipação das aparências. Como ele destaca, a partir do primeiro perfil de Kim Novak, temos a atriz isolada de relações com o ambiente, elevada e idealizada como um segredo impenetrável. Para o filósofo, Vertigo se alicerça neste "enredo típico da literatura, o enredo do fascínio pela imagem e pela força escondida atrás da imagem: a morte, a vontade de retornar ao nada"

Por outro lado, a ênfase sobre a espiral também evidencia um deslocamento sobre 
o Feminino, na maneira como Hitchcock o lapida dentro de sua carreira. Já sabemos dos curiosos entraves que o diretor criava para suas atrizes, dificultando-lhes o trabalho, mas extraindo toda a potência de suas interpretações e gestos corporais. Seus filmes marcam um notável avanço sobre a problemática feminina no cinema americano, e Vertigo, nesse sentido, é dos que mais fundo avança dentro da reflexão sobre o diálogo Mulher e Imagem. E isto, muito deve à espiral ${ }^{9}$. O tratamento elaborado sobre o corpo de Kim Novak, desde o fetiche sobre seu cabelo, nos permite uma leitura da imagem pautada pelo olhar erotômano e cinéfilo inicialmente percebido pela crítica francesa e que nos serve de basilar ponto de ligação para com os recentes filmes que hoje trazemos pelas influências de Vertigo. Guardamos o conceito para a abordagem destes filmes pela pertinência que encontram de uma construção-fetiche sobre os corpos de suas atrizes protagonistas, decupadas numa concepção especular ao que fora perpetuado em Kim Novak. Imagens de uma erótica própria e mútua, alusões do desejo e do delírio que um corpo reescrito pode despertar.

\section{Releituras de um detalhe eleito}

Pareceu-me coincidência, mas de imediato soube que não era fruto do acaso esbarrar com revisitações de Kim Novak em dois filmes de realizadores vindos de um mesmo país, em um mesmo ano de produção. Foi em 2009 que os italianos Luca Guadagnino e Dario Argento se valeram de imagens que reescreviam a memória de Novak em suas atrizes: Tilda Swinton e Emmanuelle Seigner, nos respectivos Io Sono LAAmore e Giallo. Dois trabalhos absolutamente distintos na forma e no gênero, mas interligados pelo registro que fazem deste corpo redesenhado, mito evocado. Foi espantoso constatar o grau de intimidade que estas obras guardavam para com Vertigo, não de maneira superficial ou com gratuidade, mas dentro de uma concepção muito particular e consciente de se referenciar a origem destes reflexos. É pela reconstrução da imagem-chave de Novak que atestamos a influência de Hitchcock sobre cinemas que aparentemente não trariam nada em comum, mas que se aliam em seus anseios, num momento (séc. XXI) em que a própria narrativa já não encontra meios de desenvolvimento senão retornando sobre si mesma, fazendo voltas sobre seu ponto de partida e, sinuosamente, questionando problemas emergentes da ficção no cinema contemporâneo.

A rigor, como já dito, as personagens de Tilda e Emmanuelle pouco ou nada têm em comum além de sua constituição física. Enquanto a primeira se vê envolvida numa trama romântica de adultério, a segunda atravessa um enredo de horror e violência ao tentar salvar sua irmã das mãos de um psicopata. O ponto de ligação que nos permite aproximá-las se dá pela cena em que, enfaticamente, suas imagens evocam à de Kim

9 "Já no paleolítico, uma espiral em caracol simbolizava a fecundidade aquática e lunar. Algumas peças arqueológicas têm a espiral desenhada sobre estatuetas femininas, indicando o útero (centro de vida e fertilidade)." ELIADE, Mircea. Tratado de história das religiões. São Paulo: Ed. Martins fontes, 2002. p. 232-233. 
Novak, com seu penteado em espiral: para Tilda (Fig. 2), o close sobre o cabelo é muito semelhante ao de Hitchcock, numa cena clímax em que ela persegue o jovem amigo de seu filho, com quem se envolverá sexualmente, ao tentar esconder-se numa livraria (perseguição muito semelhante à que James Stewart realizara); para Emmanuelle (Fig. 3), o recorte da câmera se dá logo no início da trama, à janela do hotel romano em que se hospeda, enquanto traja um tailleur que também rememora o figurino de Novak, pelo verde da onírica cena em que esta reaparece para Stewart. São iluminações de uma imagem referencial que ampliam a atmosfera buscada por Guadagnino e Argento, não só para suas personagens, mas para o efeito de seus dramas junto ao olhar espectador.

Apesar de Io Sono L'Amore ter como influência maior o melodrama - é Luchino Visconti o cineasta aqui retomado imagem após imagem -, não é possível desvincular o tratamento conferido à protagonista de Tilda Swinton daquele que vimos em Vertigo: a burguesa Emma (nome de um bovarismo latente) também é uma mulher que se redescobre enquanto imagem a partir do relacionamento extraconjugal, e somente a partir desta autoconsciência ela reconfigura sua compreensão de mundo e do que pensa ser a felicidade. Não por acaso, a certa altura do filme, ela deixa que o amante lhe corte o cabelo, este mesmo que abrigara a espiral, conferindo ainda mais importância ao elemento que a espelhara ao corpo de Novak.

Por sua vez, Giallo é um filme que guarda mais referências com Hitchcock, por Dario Argento ser reconhecido, desde seus primeiros filmes (nos anos 60 e 70), como um dos maiores discípulos do mestre do suspense, responsável por inúmeras e maneiristas releituras de seu legado. A questão da imagem e de sua reescrita é mesmo um ponto nuclear de Giallo, pois temos aqui um assassino que esquarteja suas belas e jovens vítimas, para lhes desfigurar a beleza dos rostos e corpos. É numa pulsão pelo grotesco que se envolve a personagem de Emmanuelle Seigner, chamada no filme de 'Linda' (pelo visto, nenhum nome é dado ao acaso), e a partir de sua busca pelo resgate da irmã sequestrada, vemos travar-se toda uma reflexão sobre a imagem do belo feminino sob a traumática perspectiva do vilão.

Situada a disparidade destes enredos, devo assumir que meu exercício comparativo também decorre de outra análise ${ }^{10}$ que veio à luz na mesma época em que tomava contato com estes dois filmes, e que agora encontra certa continuidade na observação aqui traçada. A obsessiva repetição dos penteados sobre as nucas que rege esta leitura não pode ser compreendida senão como um ponto de interpretação muito pessoal, próprio do meu olhar espectador e do que Antoine De Baecque retoma da 'Erotomania Cinéfila', qualificação crítica de François Truffaut pautada pela poética do detalhe eleito. Ora, são estas repetições que dão forma ao detalhe que elejo, que perfazem a minha concepção de cinema e a relação afetiva que tenho com as imagens de atrizes primeiramente importan-

|||||||||||||||||||||||||||||||||||||||||||||||||||||||||||||

10 Em O Drama Maquiado, artigo para o Filmologia (2011), comparamos o gesto repetido de três atrizes (Isabelle Huppert, Nicole Kidman e Juliette Binoche) em filmes distintos, como um sintoma dos rumos para o drama no cinema contemporâneo. Disponível em: http://www.filmologia.com.br/?page_id=3494 
tes para um determinado recorte do imaginário cinematográfico. Não há como escapar do contorno conceitual:

O amor pelo cinema é consubstancial ao amor dirigido às atrizes. Esse laço entre o que se vê na tela, o que se faz na vida e na cinefilia arrasta esta última para o lado da iniciação, da descoberta conjunta dos filmes e do desejo. O poder cinematográfico das mulheres na tela é frequentemente descrito como uma cena original, uma revelação do próprio cinema e do cinéfilo para si mesmo. [...] Essa visão da mulher cinematográfica é o efeito de um saber, produto de um trabalho de detecção preciso, obsessivo, e de uma análise minuciosa, maníaca, dos vestígios do que pode exceder o código sem negá-lo [...]11.

A partir disso, é possível considerar que Guadagnino e Argento são os primeiros a assumirem este 'olhar obsessivo e maníaco', diluidor de uma atmosfera original e portador de uma nova interpretação para a mis en scène elaborada por Hitchcock. Ambos se valem das imagens em que aqui nos concentramos para 'espiralar' toda uma série de elementos em suas narrativas: a começar pelas protagonistas, em suas ações e conflitos dramáticos, passando pelos desdobramentos do espaço em que transitam, dos outros personagens com quem se relacionam, assim como das imagens que as demarcam e tornam presenças singulares, pois, ainda que relacionadas sob a égide de uma cópia / refilmagem, são suficientes em sua autonomia, dentro dos filmes em que se revelam.

O símbolo da espiral, na maneira como se manifesta nestes filmes, prossegue o que pensamos a partir da noção de que a maquiagem no drama contemporâneo visa um desvio e uma reposição do olhar, na sobrevivência de um mundo cada vez mais desdramatizado. O formato do cabelo em um penteado, afinal, não deixa de coincidir com uma decisão visual sobre a apresentação que se faz do corpo, com esta consciência de um corpo-imagem que se organiza interna e externamente e, principalmente, torna-se mediado por outra consciência, ligada à câmera, ao olhar que filma e registra de maneira deslocada a inteireza destas mulheres.

É muito importante verificar o inevitável confronto advindo da avessa frontalidade que as atrizes oferecem. Para estas cenas, o que importa são suas costas, suas nucas, qualidades que não dependem unicamente de seu desempenho cênico, mas da maneira como sua encenação é atravessada pela câmera. Se retomarmos um recorte da História da Arte em que esta constante visual demarca um dos decisivos questionamentos sobre a figuração, poderemos concluir que parte da intencionalidade fílmica dos exemplos aqui

||||||||||||||||||||||||||||||||||||||||||||||||||||||||||||||

11 Amour des Femmes, Amour du Cinéma: l'érotomanie cinéphile, conferência apresentada em 2000 no Collège d'Histoire de l'Art Cinématographique, revisto e publicado em Cinefilia: invenção de um olhar, história de uma cultura, 1944-1968, tradução de André Telles, São Paulo: Cosac Naify, 2010. p. 316-317. 
refletidos está concentrada no dilaceramento do olhar, na perda ou diluição do foco narrativo, através de mecanismos que ressaltam o pôr em cena das materialidades.

O imaginário de mulheres retratadas 'de costas' na arte Moderna é um referencial que também se vincula ao que vemos em Hitchcock e nos filmes que o retomam. São exemplos que prefiguraram o espaço da abstração, que romperam com a lógica do olhar clássico para desenvolver uma nova sensibilidade de representação. Encontramos exemplos na fotografia de Félix Nadar e na pintura de Vilhelm Hammershoi (Fig. 4 e 5), de perspectivas que manipulam o feminino para confrontar os parâmetros do que se habitua como visível dentro de uma imagem. O olhar destes artistas lida com a encenação de corpos que não se pretendem completos, mas que se comportam como fragmentos, evidenciando assim uma notável consciência de seus limites. O que o cinema herda desta constituição espacial (mis en cadre) é a mis en scène de uma nostalgia, o plano como início e continuidade de uma cena potencial, mas que não se resolve e para sempre perpetua a tensão do enquadramento ${ }^{12}$.

De alguma forma, as cenas de Hitchcock, Guadagnino e Argento reescrevem o ponto de vista destes artistas que os antecederam, consciente ou inconscientemente, intensificando a circularidade de suas repetições pelo que constroem no cabelo das atrizes (ainda que fosse possível identificar um reflexo espiral já mesmo na fotografia de Nadar, pela maneira como o tecido envolve o corpo da atriz). A especularidade das imagens reunidas, como é possível ver na compilação anexa desta publicação, não deixa margem de dúvidas quanto ao que rima em suas formas. São desdobramentos que traduzem o espaço destas atrizes em códigos do tempo e do desejo, provocações ao voyeur incauto e ao regime da cópia na maneira como o compreende a Modernidade.

Possivelmente, a 'imagem móvel' de Borges encontra nos frames reunidos destes três filmes um paralelo potencial de enunciação, um ponto de encontro entre seu Menard e a eternidade. Pois, se a espiral resulta em símbolo do tempo perpétuo, também ilustra o tempo traduzido em espaço. Infindável como as mulheres que a geram, como o processo de reescrita na arte, em seu efeito palimpsesto, e como esta memória de imagens que não cessam, mas se renovam, ininterrupta e obsessivamente, para o bem de nossos olhos. 